\title{
SINGLE VISIT REVASCULARIZATION OF MATURE TEETH USING SONIC ACTIVATION PROTOCOL (A CASE SERIES)
}

\author{
Mohammed S. Hafez ${ }^{1 *}$ Msc, Nayera A. Mokhless ${ }^{2} P h D$, Amr M. Abdallah ${ }^{3} P h D$, \\ Mohamed M. Ibrahim ${ }^{4} \mathrm{PhD}$.
}

\begin{abstract} was developed to reduce the drawbacks of multiple visits. mature teeth with chronic apical periodontitis after irrigation activation using sonic disinfection protocol. composite as final restoration. Treatment outcome was evaluated for 12 months period. periapical healing radiographically. Four teeth regained vitality by the end of 12 month period. teeth with chronic apical periodontitis.

KEYWORDS: Apical periodontitis, Case series, Mature teeth, Single visit revitalization, Sonic activation.

RUNNING TITLE: Single visit revascularization in mature permanent teeth.

Assistant lecturer of Endodontics Department, Faculty of Dentistry, Pharos University in Alexandria, Alexandria, Egypt.

2 Assistant Professor of Endodontics Department, Faculty of Dentistry, Alexandria University, Alexandria, Egypt.

3 Professor Endodontics Department, Faculty of Dentistry, Alexandria University, Alexandria, Egypt.

4 Professor of Endodontics Department, Faculty of Dentistry, Alexandria University, Alexandria, Egypt.
\end{abstract}

INTRODUCTION: Revascularization has been commonly known to be limited to the immature teeth. Owing to its promising results, it was suggested as another treatment option to conventional endodontics in mature teeth. Single visit revascularization is still an area of evaluation and

OBJECTIVES: This report described the outcomes of single visit revascularization both clinically and radiographically in necrotic permanent

MATERIAL AND METHODS: Twelve cases of permanent mature teeth were recruited into the study. Canals were prepared till file X4 Protaper next system. For disinfection protocol, sonic activation (Endoactivator) was used to agitate sodium hypochlorite (2.5\%) for sixty seconds followed by $20 \mathrm{ml}$ of 17\% EDTA. The bleeding was then induced and Biodentine was placed over blood clot. Glass ionomer was used as a base then

RESULTS: Clinical evaluation and radiographic assessment were performed to evaluate the change in periapical lesion size and vitality of treated teeth to indicate treatment success. After 12 months of follow-up, all teeth showed the absence of clinical signs and/or symptoms and evidence of

CONCLUSION: Favorable outcome for single visit revascularization procedure when activated with sonic irrigation in mature single-rooted

* Corresponding Author:

E-mail: $\underline{\text { dr.mshawki@gmail.com }}$

\section{INTRODUCTION}

Regeneration is a biological procedure designed to replace the pulp-dentin complex. This field has been more focused on immature teeth treatment, as apical papilla's stem cells that show regenerative potential are located near their root apices that would help in thickening and maturation of the root to complete its closure (1).

Recently, revascularization was considered a treatment option to treat mature permanent teeth with apical periodontitis in an attempt to regain tooth vitality, even though it faces more challenges than in those found in immature teeth due to the presence of a fewer number of stem cells and narrower apical foramina to allow stem cell migration (2). The main advantage of revascularization in mature teeth is to restore natural killer cells and lymphocytes and macrophages that represent an innate immune system. This innate immunity is lost after conventional endodontic treatment may offer the potential to combat reinfections (3). The regenerated tissues may also provide more structural fracture resistance to the tooth than endodontically treated teeth (4).

Single-visit revascularization protocols have been developed to reduce intracanal medications' potential drawbacks, including discoloration, difficulty of removal from the canal and toxicity to stem cells of the apical papilla $(5,6)$. Calcium hydroxide dressing is one of intracanal medications used for multiple visit revascularization, one of its drawback that it is less effective than antibiotic paste formulations against some intracanal bacteria (7). Triple antibiotic pastes and double antibiotic pastes are also used as intracanl medications, however at the paste-like concentrations typically used in regenerative endodontic procedures are lethal in direct contact with stem 
cells and may trigger the destruction of stem cells of the apical papilla placed in a scaffold within the root canal lumen $(8,9)$. Shin et al. (10) were the first to attempt a revascularization case completed in one visit for an immature tooth. Sodium hypochlorite irrigation (6\%) was used to disinfect the canal, followed by MTA to seal the canal orifices. It was stated that the advantages of single visit revascularization are reduction of the chance of additional bacterial contamination, overcome the problem of poor patient follow-up visits compliance, and it can help to combat potential injury of the tooth and avoid unnecessary drawbacks from intracanal medications used (11).

The irrigation protocol is essential in improving the effectiveness of disinfection and cleaning of the necrotic canals to achieve an adequate environment to allow successful single revascularization. EndoActivator (Dentsply Tulsa Dental Specialties, Tulsa, OK) is an irrigation system that offers forcefully streaming at a specific sonic frequency $(190 \mathrm{~Hz})$ that enhances irrigation in lateral canals at the apical third as compared with conventional needle irrigation and can remove biofilm and smear layer inside curved canals of molar teeth $(12,13)$. Up to our knowledge, neither clinical trials nor case reports investigated the effect of irrigation activation using Endoactivator and its impact on the success of single visit revascularization in mature teeth. The present case series aimed to evaluate the radiographic and clinical outcome of single visit revascularization in mature permanent teeth aided with sonic activation irrigation protocol.

\section{MATERIALS AND METHODS}

The study's protocol was accepted by the research ethics committee of the Faculty of Dentistry, Alexandria University, with institutional review board number 00010556-IORG 0008839. When a patient met the study's inclusion/exclusion criteria, the objectives, benefits, and risks of the study were discussed with the patient. Consent (Oral and written) was obtained from all the study participants.

Eligibility Criteria

Twelve teeth consisted of eleven maxillary teeth (five central incisors, two lateral incisors, and four canines) and one mandibular incisor tooth of adult female and / or male patients, age range of 18-45 years and free from any medical conditions (Table 1)

Table (1): Demographic and clinical data of the treated patients.

\begin{tabular}{|l|c|c|}
\hline & No. & $\%$ \\
\hline Sex & \multicolumn{2}{|c|}{} \\
Male & 4 & 44.4 \\
Female & 5 & 55.6 \\
\hline Age (years) & \multicolumn{2}{|c|}{$21.0-41.0$} \\
Min. - Max. & \multicolumn{2}{|c|}{$28.58 \pm 6.68$} \\
Mean \pm SD. & 11 & 91.7 \\
\hline Teeth & 1 & 8.3 \\
Maxillary & 10 & 83.3 \\
Mand & 2 & 16.7 \\
\hline Etiology & 1 & \\
Trauma & & \\
Caries & & \\
\hline
\end{tabular}

Inclusion criteria

1- Mature single rooted teeth (single canal) with complete apical closure.

2- Non vital permanent teeth.

3- Presence of periapical radiolucency.

4- Periodontally sound teeth.

Exclusion criteria

1- Teeth with root fractures.

2- Previous root canal treatment.

3- Teeth with root resorption (Internal or External).

4- Diabetic, hypertensive or immunocompromised patients.

\section{Patient Examination}

Patients meeting the eligibility criteria of the study were recruited from the out-patient clinic of the Faculty of Dentistry, Alexandria University starting from September 2018. Clinical examinations were performed, including percussion, palpation, periodontal pocket depth measurement, sensibility tests, and presence of a sinus tract (No teeth selected presented with sinus tract). Cold test using ethyl chloride spray (Walter Ritter, Hamburg, Germany) and electric pulp testing (Parkell; Digitest Pulp Vitality Tester, Brentwood, NY) were applied to confirm the diagnosis. Radiographic examination including preoperative periapical radiographs (Apixia psp scanner, Apixia Corp, Southern California, United States) (Fig 1A) to confirm periapical lesion presence using parallel device XCP- DS FIT universal holder (Dentsply Tulsa Dental Specialties, Tulsa, USA) and preoperative CBCT scan (J Morita Mfg corp., Kyoto, Japan) (Fig 1D \& 1E).
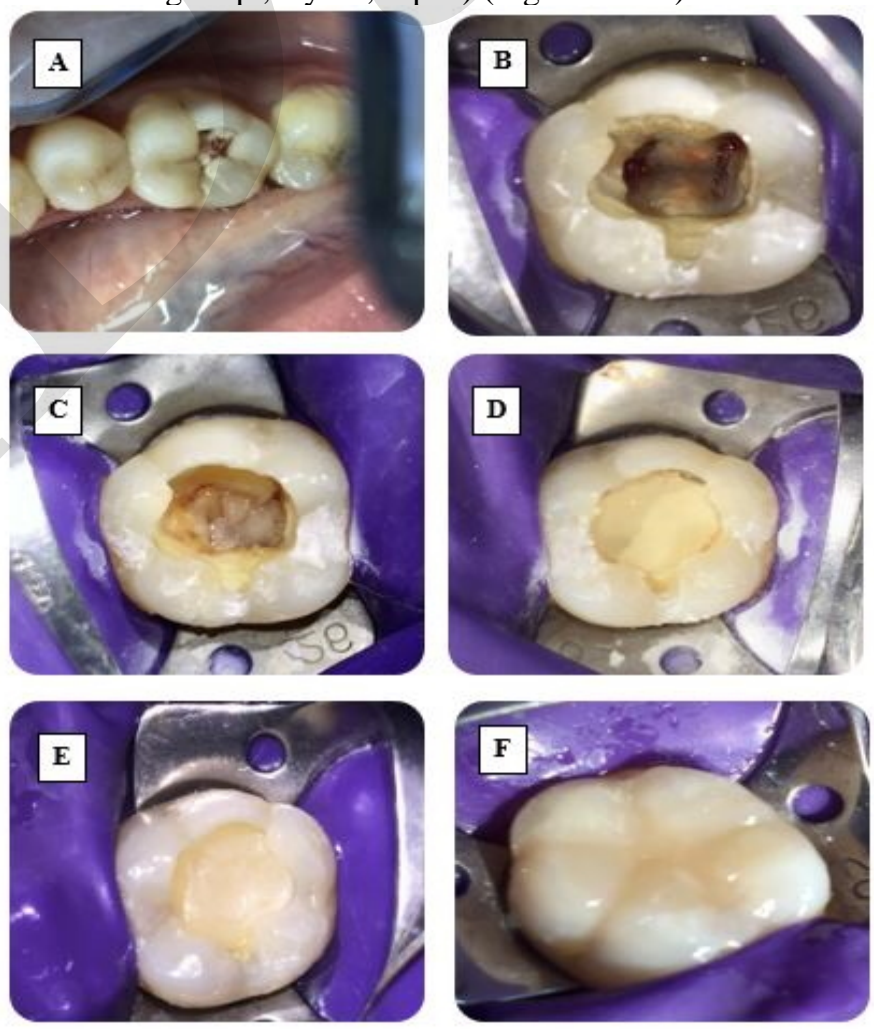

Figure 1

A: Showing a carious lesion on the occlusal surface of tooth \#46.

B: Removal of coronal pulpal tissues and hemostasis achieved.

C: PRF plug was placed over the remaining radicular pulp.

D: Biodentine was placed over the PRF plug.

E: RMGIC placed over the Biodentine.

F: Composite restoration as a final restoration. 

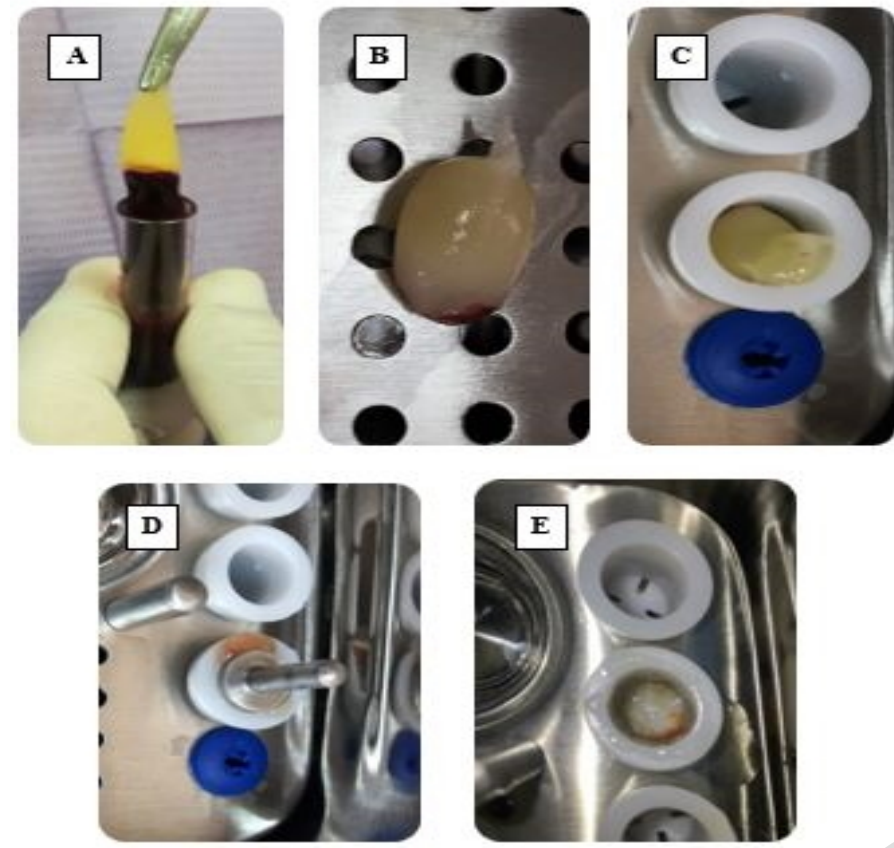

Figure 2

A: Showing a sterile artery forceps inserted into the test tube to retrieve the PRF clot.

B: PRF clot placed in the PRF box.

C: PRF clot was placed in one of the cylinders of the PRF box.

$\mathrm{D}$ : The piston was compressed gently to pack the PRF clot to form PRF plug.

E: PRF plug at the base of the PRF box cylinder.
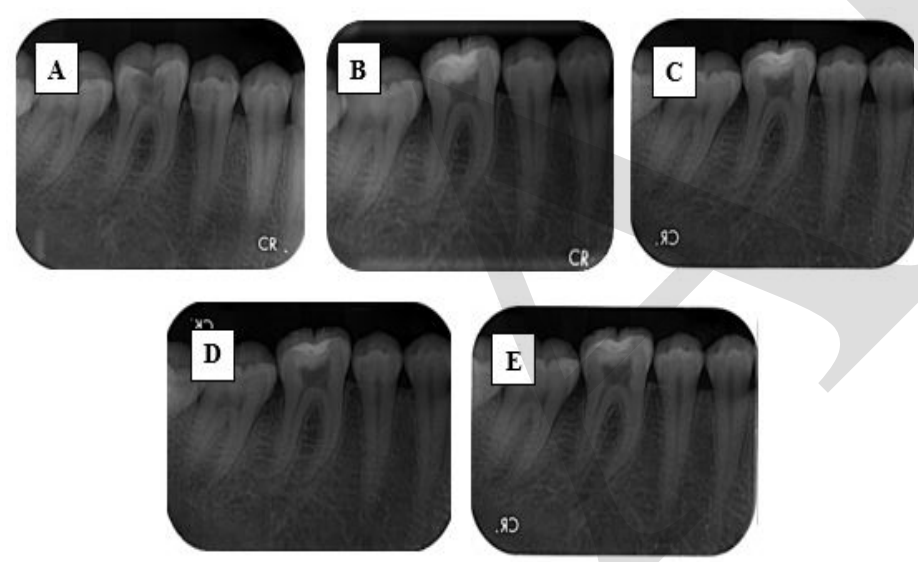

Figure 3

A: A pre-operative radiograph with a large carious lesion approaching the pulp.

B: Immediate post-operative radiograph showing maintenance of the pulp chamber space using PRF.

C: Three-month follow-up radiograph showed normal trabeculation of bone around the tooth.

D: Six-month follow-up radiograph showed normal trabeculation of bone around the tooth.

E: Twelve-month follow-up radiograph showed normal trabeculation of bone around the tooth.

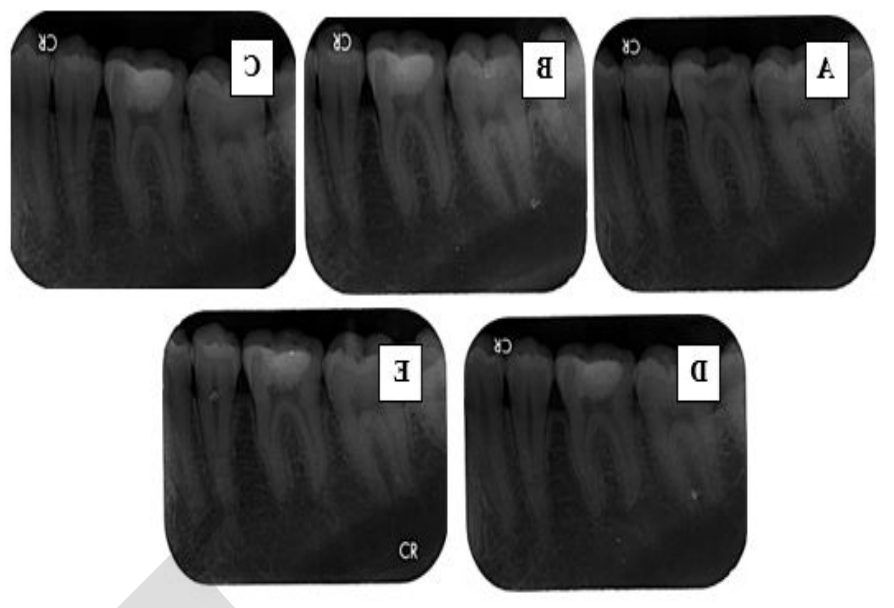

Figure 4

A: A pre-operative radiograph with a large carious lesion approaching the pulp with widening of the PDL space around both roots.

B: Immediate post-operative radiograph showing maintenance of the pulp chamber space using PRF.

C: Three-month follow-up radiograph showed normal trabeculation of bone around the tooth with normal PDL space around both roots. D: Six-months follow-up radiograph showed normal trabeculation of bone around the tooth with normal PDL space around both roots. E: Twelve-months follow-up radiograph showed normal trabeculation of bone around the tooth with normal PDL space around both roots.

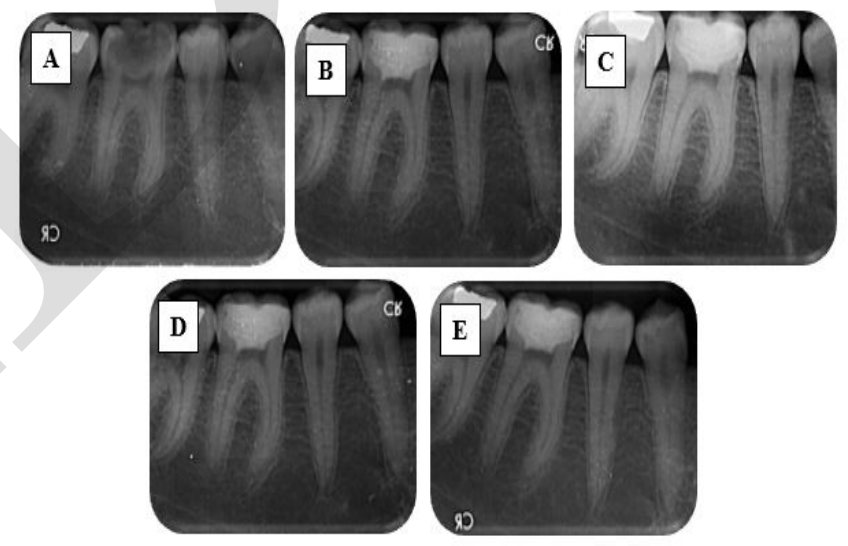

Figure 5

A: A pre-operative radiograph with a large carious lesion approaching the pulp with widening of the PDL space around the mesial root. $\mathrm{B}$ : Immediate post-operative radiograph showing maintenance of the pulp chamber space using PRF.

C: Three-month follow-up radiograph showed normal trabeculation of bone around the tooth with normal PDL space around both roots D: Six-month follow-up radiograph showed normal trabeculation of bone around the tooth with normal PDL space around both roots.

E: Twelve-month follow-up radiograph showed normal trabeculation of bone around the tooth with normal PDL space around both roots.

\section{Treatment Procedures}

Single experienced endodontist performed all the clinical procedures of the study. Scandonest 3\% Mepivacaine without vasoconstrictor (Septodont, Saint-Maur-des-Fosses, France) was used as local infiltration for the involved tooth. Isolation 
using a rubber dam was applied, and an access cavity was then performed. Working length was obtained using apex locator (J Morita Mfg corp., Kyoto, Japan) and was confirmed with a radiograph. Glide path was achieved with a size 10,15 K-type file (Dentsply Maillefer, Ballaigues, Switzerland). The canal preparation was then completed using ProTaper Next system (Dentsply Maillefer, Ballaigues, Switzerland) by the sequence of X1, X2, X3, and X4 according to the manufacturer's recommendation (14).

A total amount of $20 \mathrm{ml}$ of $2.5 \%$ sodium hypochlorite were used in a sequence of $5 \mathrm{ml}$ after each Protaper next file (Dentsply Maillefer, Ballaigues, Switzerland). For the disinfection protocol, additional $2 \mathrm{ml}$ of $2.5 \%$ sodium hypochlorite was used to irrigate the canals and agitated using EndoActivator (Dentsply Maillefer, Ballaigues, Switzerland) Blue Tips size (35/04) for 60 seconds at 10,000 cycles per minute (1 mm shorter than the working length) according to manufacturing instruction (15). Saline (15ml) was then used for flushing the canals, followed by $20 \mathrm{ml}$ of $17 \%$ EDTA solution (Dia-Prep Plus, Diadent Group International Inc., Chongju, Korea) for one minute. The apical foramen using file size 40 and then file size 20 (Dentsply Maillefer, Ballaigues, Switzerland) was introduced $2 \mathrm{~mm}$ beyond working length to invoke bleeding in the canal by irritating the apical tissues. The bleeding was stopped $2 \mathrm{~mm}$ below the CEJ level and left for $10 \mathrm{~min}$ to allow clotting (16). A mixture of Biodentine (Septodont, Saint-Maur-des-Fosses, France) was then applied according to the manufacturer's instructions and packed over the blood clot using endodontic pluggers. After 15 min, glass ionomer restoration (GC Fuji II LC, GC Corp, Tokyo, Japan) was placed and then covered by final composite restoration (Nexcomp; Metabiomed, Chungcheongbukdo, South Korea).

Follow-ups

All patients were recalled to the clinic for clinical and radiographic evaluation (Apixia psp scanner, Apixia Corp, Southern California, United States) till the twelve months followup. The vitality of all teeth after 12 months were evaluated using both cold test and electric pulp testing. Radiographic assessment using Periapical index score (17) and CBCT scoring index (18) was performed using digital X-ray (Fig 1B, 1C) and CBCT scan (Fig 2F \& 2G) respectively to evaluate the change of the size of periapical lesion. According to the result of clinical and radiographic evaluation, the patients were categorized into the following categories (19); a) Healed (No pain, discomfort or altered sensation, vitality tests and radiographically similar to contralateral control teeth), b) Healing (No pain, discomfort or altered sensation, no response to vitality tests and radiographically consistent with contralateral tooth) and c) Persistent disease (Pain, discomfort or altered sensation, no response to vitality tests and radiographically is inconsistent with contralateral tooth). Statistical analysis

Data were fed to the computer and analyzed using IBM SPSS software package version 20.0. (Armonk, NY: IBM Corp). The Kolmogorov-Smirnov test was used to verify the normality of the distribution. Quantitative data were described using range (minimum and maximum), mean, standard deviation, median and interquartile range (IQR). Wilcoxon signed ranks tests were used for abnormally distributed quantitative variables to compare between two periods. The significance of the obtained results was judged at the $5 \%$ level.

\section{RESULTS}

Clinical assessment of the treatment outcome showed no clinical signs and symptoms, no history of pain, discomfort, or altered sensation at the end of 12 months follow-up period for all treated teeth. Also, all treated teeth showed no discoloration throughout the follow-up period. Four teeth (33.3\%) were considered "Healed" since they responded positively for both vitality tests (cold and electric pulp tests), eight teeth were considered "Healing" (66.6\%) since they showed no signs of vitality; however, healing of the periapical lesion was noted and none considered with "Persistence disease". There was a statistically significant reduction in the size of the periapical lesion evaluated by both Periapical index score $(\mathrm{P}<0.001)$ and CBCT scoring index $(\mathrm{P}<0.002)$ between baseline and 12 months follow up periods for all teeth (Table 2). All these results indicate the success of the treatment protocol in the treated teeth.

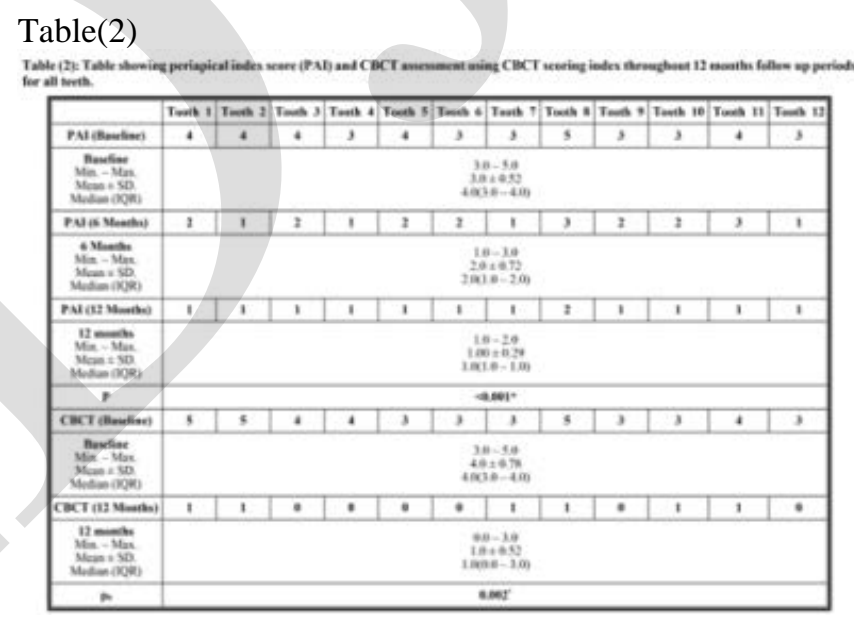

\section{DISCUSSION}

Non-vital permanent mature teeth with chronic apical periodontitis are usually treated with non-surgical root canal treatment (NSRCT) because of the predictability of treatment outcome (20). However, revascularization has been suggested as an additional successful treatment option for permanent necrotic teeth with apical periodontitis. This treatment resulted in the resolution of clinical signs/symptoms and apical periodontitis $(2,21)$.

The increase of age causes physiological changes as the apical cementum's thickening and change in the apical foramina position, which may affect mesenchymal stem cell's migration into the canal (22). However, in the current case series, the patient's age ranged from 21 to 41 years, and the results showed a successful outcome at this wide age range.

The study's treated teeth were mechanically prepared to the radiographic apex to clean the canal from necrotic tissues and bacteria. Lin et al. (23) stated that the main cause of failure in 
regenerative endodontic therapy was the biofilm that remains attached to the canal walls due to the lack of mechanical preparation. ProTaper Next system was selected in the present study because its design gives a snake-like motion inside the canal, leading to irrigation activation, and showed less extrusion of debris than manual and other rotary systems (24). In the current case series, apical size enlargement to size 0.40 $\mathrm{mm}$ was performed using a size 40 file to ensure apical widening beyond the apical seat formed by X4 file preparation to facilitate bleeding flow in the canal. This apical diameter was considered adequate for both stem cell migration and tissue ingrowth inside the canal meanwhile preserve sufficient apical dentin for the creation of apical stop in case of failure of regenerative endodontic therapy (25). Fang et al. (26) showed that teeth with pulp necrosis having an apical size less than $0.5 \mathrm{~mm}$ reached $90 \%$ clinical success. On the other hand, Abou-Samra et al. (27) and Saoud et al. (2) showed successful treatment outcomes for permanent maxillary incisor teeth with apical sizes of 35 and 30, respectively.

To achieve efficient irrigation and disinfection needed for the canal in a single visit treatment, sodium hypochlorite (2.5\%) have been recommended in the present case series to avoid cytotoxic effect on stem cells and denaturation of growth factors. This was in accordance with Zehnder (28), who recommended the use of $2.5 \%$ sodium hypochlorite and stated that it offered the best compromise between efficiency and lack of toxicity. In addition, Fouad (29) stated that high concentrations of sodium hypochlorite, such as $5.25 \%$, cause the denaturation of the growth factors embedded in the dentin, which is essential in revascularization. This was inconsistent with Shin et al. (8), who used 6\% sodium hypochlorite for disinfection of an immature tooth's canal in a single-visit revascularization protocol and obtained a successful outcome. EDTA solution (17\%) was used for the final flush of the canals. This was in accordance with Galler et al. (30), who stated that $17 \%$ EDTA solution aids in the release of growth factors due to its chelating action. In addition, Trevino et al. (31) stated that EDTA promoted SCAP survival and removed the first layer of dentin, which is rich in $\mathrm{NaOCl}$ that shows undesirable effects on the stem cells.

Single visit treatment is a controversial line of treatment, especially in revascularization protocol. The control of the level of bacteria inside the canal is an essential factor impacting its success. However, the ability to mechanically instrument the canals in mature teeth aided with sonic irrigation activation helps control bacterial levels. It improves the success rates of the treatment outcome. Gu et al. (32) stated that single visit treatment reduces the chance of bacterial contamination in the canal space in-between visits, overcome the problem of poor compliance with follow-ups, and helping avoiding potential injury of the tooth from multiple visits. The present study results was in consistence with Banchs and Trope (33), Shin et al. (8), and Aldakak et al. (34), who performed successful single visit revascularization in immature teeth, unlike our study, which was done on mature teeth.

EndoActivator was used in an attempt to enhance the success rate of single-visit treatment. It initiates cavitation effect and acoustic streaming that increases the irrigant's penetration into areas of the root canals system that are less accessible, helping more in eradicating bacteria, thus better disinfection achieved $(9,35)$. Biodentine was used as a coronal plug in the present cases because it has similar biocompatibility as MTA but without causing tooth discoloration (36).

The successful outcome both clinically and radiographically for the treated teeth is encouraging since, to our knowledge, this might be the first case series for single visit revascularization on mature teeth. In the present study, four teeth showed positive results for both cold and electric pulp tests, indicating signs of revascularization and possible reorganization of nerve endings inside the canal. This was in accordance with Paryani and Kim (1) and Nageh et al. (37), who showed that sixty percent of their treated teeth established tooth vitality after twelve months follow up, which indicated revitalization of the teeth. Moreover, Arslan et al. (38) stated that a positive result to electric pulp testing in fifty percent of the treated cases with revascularization was noted. Furthermore, El-Kateb et al. (39) treated eighteen mature teeth with apical periodontitis using double visit revascularization protocol. They showed $83 \%$ and $77 \%$ of the treated cases positively responded to cold and electric pulp tests, respectively, at the 12 months follow up period. It was also confirmed the reorganization of vital tissue inside the canals of the treated teeth using MRI. However, the present case series results were against Saoud et al. $(2,40,41)$ and Nagas et al. (42), who reported negative responses to vitality tests in mature teeth after the twenty-six and sixty months follow-up period, respectively. Radiographic assessment using both the Periapical index score and CBCT scoring index was essential for evaluating lesion size, which was an important indicator of treatment success. The Periapical index score was selected following Ørstavik et al. (17). Evaluation of periapical tissues ranging from normal tissue (score 1) to severe apical periodontitis (score 5). However, the Periapical index score uses 2-dimensional radiographic images for evaluation, subsequently offering a less accurate interpretation of the periapical lesions. Therefore, the CBCT scoring index (18) was selected for the 3-dimensional interpretation of the periapical lesions to increase the measurement accuracy and allow more in-depth evaluation. This was in accordance with Saoud et al. (21) and El-Kateb et al. (39), where both methods (CBCT and periapical radiograph) were used to evaluate the change in the size of the periapical lesion after the regenerative procedure. On the other hand, Paryani K, Kim SG (1), Abou-Samra et al. (27), and Nageh et al. (37) depended only on the periapical radiograph for the evaluation of periapical lesion healing.

Teeth in the present case series presented an evident reduction in periapical lesion size after twelve months. It may be attributed to the fact that revascularization treatment promoted the host wound healing process by enhancing the regenerated tissues' immune defense response (2). It could be debated that the periapical healing resulted from the canal's disinfection and tight coronal seal only. However, positive vitality results obtained in four treated teeth indicates revascularization success. These results were in agreement with Paryani K, Kim SG (1), Abou-Samra et al. (27), and Nageh 
et al. (37), who reported healing of periapical lesions in revascularization treatment of mature non-vital teeth with apical periodontitis, indicating the success of the treatment.

To sum up, several studies had obtained successful single visit revascularization for immature teeth. However, more indepth studies with larger sample sizes and other irrigation activation protocols in the field of mature single visit revascularization teeth should be encouraged to obtain both advantages of revascularization of mature teeth with its aforementioned advantages along with rapid and less costly single visit treatment $(10,27)$.

\section{CONCLUSION}

Within the limitation of this case series and based on the positive outcome of the treated cases, it was concluded that revascularization and healing of chronic apical periodontitis in mature permanent teeth could be achieved from single-visit treatment with sonic disinfection protocol in mature permanent teeth. More extended follow-up periods are needed to confirm its results and compare its efficacy with different irrigation activation techniques.

\section{CONFLICT OF INTEREST}

The authors declare that they have no conflicts of interest.

\section{Funding}

The authors received no specific funding for this work.

\section{REFERENCES}

1. Paryani K, Kim SG. Regenerative endodontic treatment of permanent teeth after completion of root development: A report of 2 cases. J Endod. 2013;39:929-34.

2. Saoud TM, Martin G, Chen YHM, Chen KL, Chen CA, Songtrakul K, et al. Treatment of mature permanent teeth with necrotic pulps and apical periodontitis using regenerative endodontic procedures: a case series. J Endod. 2016;42:57-65.

3. Saghiri MA, Asatourian A, Sorenson CM, Sheibani N. Role of angiogenesis in endodontics: contributions of stem cells and proangiogenic and antiangiogenic factors to dental pulp regeneration. J Endod. 2015;41:797-803.

4. Sedgley CM, Messer HH. Are endodontically treated teeth more brittle? J Endod. 1992;18:332-5.

5. Ruparel NB, de Almeida JF, Henry MA, Diogenes A. Characterization of a stem cell of apical papilla cell line: effect of passage on cellular phenotype. J Endod. 2013;39:357-63.

6. Berkhoff JA, Chen PB, Teixeira FB, Diogenes A. Evaluation of triple antibiotic paste removal by different irrigation procedures. J Endod. 2014;40:1172-7.

7. Sabrah AH, Yassen GH, Gregory RL. Effectiveness of antibiotic medicaments against biofilm formation of Enterococcus faecalis and Porphyromonas gingivalis. J Endod. 2013;39:1385-9.

8. Ruparel NB, Teixeira FB, Ferraz CC, Diogenes A. Direct effect of intracanal medica- ments on survival of stem cells of the apical papilla. J Endod 2012;38:1372-5.
9. Althumairy RI, Teixeira FB, Diogenes A. Effect of dentin conditioning with intracanal medicaments on survival of stem cells of apical papilla. J Endod. 2014;40:521-5.

10. Shin SY, Albert JS, Mortman RE. One step pulp revascularization treatment of an immature permanent tooth with chronic apical abscess: a case report. Int Endod J. 2009;42:1118-26.

11.Gu LS, Kim JR, Ling J, Choi KK, Pashley DH, Tay FR. Review of contemporary irrigant agitation techniques and devices. J Endod. 2009;35:791-804.

12. de Gregorio C, Estevez R, Cisneros R, Heilborn C, Cohenca N. Effect of EDTA, sonic, and ultrasonic activation on the penetration of sodium hypochlorite into simulated lateral canals: an in vitro study. J Endod. 2009;35:891-5.

13. Caron G. Cleaning efficiency of the apical millimetres of curved canals using three different modalities of irrigant activation: an SEM study. M.Sc. Thesis. Paris VII University, Paris. France. 2007.

14. Martins MP, Duarte MA, Cavenago BC, Kato AS, da Silveira Bueno CE. Effectiveness of the ProTaper Next and Reciproc Systems in Removing Root Canal Filling Material with Sonic or Ultrasonic Irrigation: A Micro-computed Tomographic Study. J Endod. 2017;43:467-71.

15. Helmy RH, Mokhless NA, El Backly RM. In Vitro Comparative Efficacy of Two Techniques for Irrigant Delivery in Curved Root Canals. Alex Dent J. 2016;41:314-7.

16. American Association of Endodontists. AAE Clinical Considerations for a Regenerative Procedure. 2016. Available at: http://www.aae.org//current regenerative endodontic considerations.pdf. Accessed on 1/11/ 2017.

17. Ørstavik D, Kerekes K, Eriksen HM. The periapical index: a scoring system for radiographic assessment of apical periodontitis. Endod Dent Traumatol. 1986;2:20-34.

18. Estrela C, Bueno MR, Azevedo BC, Azevedo JR, Pécora JD. A new periapical index based on cone beam computed tomography. J Endod. 2008;34:1325-31.

19. Witherspoon D, Small J, Harris G. Mineral trioxide aggregate pulpotomies A case series outcomes assessment. JADA. 2006;137:610-8.

20.Ng YL, Mann V, Gulabivala K. Outcome of secondary root canal treatment: a systemic review of the literature. Int Endod J. 2008;41:1026-46.

21. Saoud TM, Sigurdsson A, Rosenberg PA, Lin LM, Ricucci D. Treatment of a large cystlike inflammatory periapical lesion associated with mature necrotic teeth using regenerative endodontic therapy. J Endod. 2014;40:2081-6.

22. Morse DR. Age-related changes of dental pulp complex and their relation to systemic aging. Oral Surg Oral Med Oral Pathol. 1991;72:721-45.

23. Lin LM, Shimizu E, Gibbs JL, Loghin S, Ricucci D. Histologic and histobacteriologic observations of failed revascularization/revitalization therapy: a case report. J Endod. 2014;40:291-5.

24. Van Der Vyver PJ, Scianamblo MJ. Clinical guidelines for the use of ProTaper Next instruments (part I). Dent Trib. 2014;7:12-6. 
25. Estefan BS, El Batouty KM, Nagy MM, Diogenes A. Influence of age and apical diameter on the success of endodontic regeneration procedures. J Endod. 2016;42:1620-4.

26. Fang Y, Wang X, Zhu J, Su C, Yang Y, Meng L. Influence of Apical Diameter on the Outcome of Regenerative Endodontic Treatment in Teeth with Pulp Necrosis: A Review. J Endod. 2018;44:414-31.

27. Abou Samra RA, El Backly RM, Aly HM, Nouh SR, Moussa SM. Revascularization in mature permanent teeth with necrotic pulp and apical periodontitis: case series. Alex Dent J. 2018;43:7-12.

28. Zehnder M. Root canal irrigants. J Endod. 2006;32:389-98.

29. Fouad AF. Microbial factors and antimicrobial strategies in dental pulp regeneration. J Endod. 2017;43:46-50.

30. Galler KM, Souza RN, Federlin M, Cavender AC, Hartgerink JD, Hecker S. Dentin conditioning codetermines cell fate in regenerative endodontics. J Endod. 2011;37:1536-41.

31. Trevino EG, Patwardhan AN, Henry MA, Perry G, Dybdal-Hargreaves N, Hargreaves KM, et al. Effect of irrigants on the survival of human stem cells of the apical papilla in a platelet-rich plasma scaffold in human root tips. J Endod. 2011;37:1109-15.

32. Gu LS, Kim JR, Ling J, Choi KK, Pashley DH, Tay FR. Review of contemporary irrigant agitation techniques and devices. J Endod 2009;35:791-804.

33. Banchs F, Trope M. Revascularization of immature permanent teeth with apical peri- odontitis: new treatment protocol? J Endod. 2004;30:196-200.

34. Aldakak MM, Capar ID, Rekab MS, Abboud S. Singlevisit pulp revascularization of a nonvital immature permanent tooth using Biodentine. Iran Endod J 2016;11:246-9.

35. Khalap ND, Kokate S, Hegde V. Ultrasonic versus sonic activation of the final irrigant in root canals instrumented with rotary/reciprocating files: An in-vitro scanning electron microscopy analysis. J Conserv Dent. 2016;19:368-72.
36. Camilleri J. Staining Potential of Neo MTA Plus, MTA Plus, and Biodentine Used for Pulpotomy Procedures. J Endod. 2015;41:1139-45.

37. Nageh M, Ezzat K, Ahmed G. Evaluation of cervical crown/root fracture following PRF revascularization versus root canal treatment of non-vital anterior permanent teeth with closed apex (Randomized clinical trial). Int J Adv Res. 2017;5:810-8.

38. Arslan H, Ahmed HMA, Şahin Y, Doğanay Yıldız E, Gündoğdu EC, Güven Y, et al. Regenerative endodontic procedures in necrotic mature teeth with periapical radiolucencies: a preliminary randomized clinical study. J Endod. 2019;45:863-72.

39. El-Kateb NM, El-Backly RN, Amin WM, Abdalla AM. Quantitative Assessment of Intracanal Regenerated Tissues after Regenerative Endodontic Procedures in Mature Teeth Using Magnetic Resonance Imaging: A Randomized Controlled Clinical Trial. J Endod. 2020;46:563-74.

40. Saoud TM, Huang GT, Gibbs JL, Sigurdsson A, Lin LM. Management of teeth with persistent apical periodontitis after root canal treatment using regenerative endodontic therapy. J Endod. 2015;41:1743-8.

41. Saoud TMA, Ricucci D, Lin LM, Gaengler P. Regeneration and Repair in Endodontics-A Special Issue of the Regenerative Endodontics-A New Era in Clinical Endodontics. Dent J (Basel). 2016;27;4:3.

42. Nagas E, Uyanik MO, Cehreli ZC. Revitalization of necrotic mature permanent incisors with apical periodontitis: a case report. Restor Dent Endod. 2018;43:31. 